\title{
APUNTES SOBRE EL TRÁFICO ILEGAL DE ESCLAVOS HACIA BRASIL Y URUGUAY: LOS “COLONOS” AFRICANOS DE MONTEVIDEO (1832-1842)
}

\author{
On the Illegal Slave Trade to Brazil \\ and Uruguay: The African "Colonists" of \\ Montevideo (1832-1842)
}

Alex Borucki*

\begin{abstract}
RESUMEN
El caso de los "colonos" africanos de Montevideo ilustra la renovación de las redes de tráfico de esclavos entre los portugueses y españoles del Atlántico sur. Estas redes, que habían canalizado la llegada legal e ilegal esclavos al Río de la Plata colonial, continuaron vigentes hacia la década de 1830 y facilitaron el arribo de esclavos a Rio de Janeiro justo cuando la política anti-esclavista británica y el gobierno brasileño estaban tratando de cortar ese tráfico. Este artículo revela cómo algunos traficantes brasileños crearon una operación coordinada de tráfico de esclavos, bajo el nombre de "colonos africanos," que involucró a comerciantes de Luanda, Mozambique, Rio de Janeiro y Montevideo en la década de 1830. Los "colonos" africanos de Montevideo no sólo fueron la última generación de esclavos que arribó al Uruguay traída directamente de África, sino también los últimos africanos esclavizados llegados a las nuevas repúblicas de la América española continental.
\end{abstract}

Palabras-clave: tráfico de esclavos; Brasil; Uruguay; siglo XIX.

\section{ABSTRACT}

The case of the African "colonists" of Montevideo illustrates the rebirth of slave trading networks between the Portuguese and Spanish of the

* Doutorando pela Emory University. E-mail: aboruck@gmail.com. 
South Atlantic. These networks, which had legally and illegally brought slaves to the colonial Rio de la Plata, were still active in the years 1830s. They contributed to the arrival of slaves in Rio de Janeiro just as the British anti-slave trade policy and the Brazilian government tried to end this traffic. This article uncovers a slave trading operation designed by Brazilian merchants which connected Luanda, Mozambique, Rio de Janeiro and Montevideo by the 1830s. The African "colonists" of Montevideo were not only the last generation of slaves directly brought from Africa to Uruguay, but also the last enslaved Africans who arrived in any of the new republics of mainland Spanish America.

Key words: slave trade; Brazil; Uruguay; $19^{\text {th }}$ Century.

Una de las medidas más importantes para finalizar el tráfico transatlántico de esclavos ocurrió en 1830, cuando Brasil y Gran Bretaña implementaron un tratado para finalizar el vasto tráfico de esclavos brasileño ${ }^{1}$. Poco después, entre 1832 y 1838, misteriosos barcos portugueses arribaron a Montevideo desde África, teniendo lastre como única carga. La prensa local sospechó que estos navíos habían desembarcado esclavos en Rio de Janeiro antes de llegar a Montevideo, y que estas actividades violaban de alguna manera la prohibición del tráfico de esclavos en Uruguay, en donde la trata se había ilegalizado sucesivamente en 1825 y 1830 . El cónsul británico en Montevideo tomó nota de alguno de estos barcos y los denunció como navíos esclavistas vacíos que estaban en ruta desde o hacia Brasil. No obstante, la bien conocida lista de viajes esclavistas publicada por la cancillería británica en 1845 registró a estos barcos como desembarcando esclavos en Montevideo en lugar de en Rio de Janeiro². De hecho, estos navíos eran parte de una operación que trajo esclavos a Brasil y también disfrazó el envío de africanos a Montevideo bajo el título de "colonos" para evadir la legislación antiesclavista uruguaya.

Antes de la liquidación formal de la trata en Brasil (1830), los traficantes de esclavos brasileños se apuraron a traer tantos esclavos como

1 Sobre las nuevas miradas en torno a la ley de 1831 y su aplicación a la prohibición del tráfico de esclavos brasileño ver: Dossiê - "Para inglês ver"? Revisitando a Lei de 1831, publicado por Estudos Afro-Asiáticos, ano 29, n. 1/2/3, p. 87-340, jan.-dez. 2007.

2 Great Britain, Parliamentary Papers, 1845, XLIX. Philip D. Curtin aceptó este registro como prueba genuina de arribos esclavistas en Montevideo. CURTIN, Philip D. The Atlantic Slave trade: A Census. Madison: Univ. of Wisconsin Press, 1969, p. 249. 
fuera posible al Imperio. Estos mercaderes también comenzaron a desarrollar nuevas estrategias para evadir las patrullas británicas en el Atlántico. Algunos traficantes planearon introducir "colonos africanos libres" al Brasil inmediatamente después el final de la trata establecido para 1830. Estos comerciantes se proponían comprar esclavos en África, luego liberarlos, y embarcarlos hacia Brasil, en donde los africanos tendrían que trabajar para pagar su manumisión y el costo del pasaje transatlántico. El término "colono" designaba una especie de inmigrante contratado que trabajaba en su lugar de destino para pagar su trasporte. A través de esta operación, los traficantes anticiparon poder eludir las patrullas navales británicas ya que los africanos en teoría viajarían por su propia voluntad ${ }^{3}$. Los representantes británicos en Brasil señalaron al gobierno británico que sería difícil impedir este tráfico de esclavos disfrazado ${ }^{4}$. El canciller británico Lord Aberdeen consideró esta cuestión simplemente como un subterfugio para la continuación del tráfico esclavista, y advirtió al gobierno brasileño que todas las naves brasileñas que llevaran grupos de africanos a Brasil, ya fueran esclavos o colonos, serían consideradas como una violación al tratado de 1826 contra la trata ${ }^{5}$. No obstante, los comerciantes brasileños de esclavos aplicaron el esquema de "colonos" africanos al vecino Uruguay, que había logrado su independencia tras la guerra Argentino-Brasileña (1825-1828).

En Uruguay, el gobierno local contrató con mercaderes brasileños la introducción de "colonos" africanos en 1832-1834. Los traficantes pagaron una enorme suma al gobierno para obtener la licencia para introducir estos "colonos", que tenían que ser menores de 16 años. Una vez en Uruguay, los mercaderes vendían el derecho sobre el trabajo de estos "colonos" para cubrir los gastos de su transporte más los dividendos. Este operativo permitió el desembarco de niños africanos en Montevideo para servir como esclavos. En Montevideo, las contradicciones entre la edad de estos colonos, la mayoría niños, y la condición de colonos libres, dejaba en evidencia a la empresa esclavista. Asimismo, los traficantes brasileños utilizaron el subterfugio de los "colonos" africanos para defenderse en los casos en que sus naves fueran capturadas y enviadas a la Corte de Comisión

3 British National Archives, Foreign Office 84 (en adelante BNA, FO 84) /95, Aberdeen a Aston, 7 Diciembre de 1829; BNA, FO 84/112, Pennell a Aberdeen, 23 enero y 30 Abril 1830.

4 BNA, FO 84/95, Pennell a Aberdeen, 30 abril 1830.

5 BNA, FO 84/95, Aberdeen a Aston, 7 diciembre 1829. 
Mixta Anglo-Brasileña, y de este modo recuperar los navíos esclavistas capturados por la armada británica.

Este artículo explora los eventos que durante y después de la independencia de Uruguay influenciaron en el arribo de esclavos hacia Rio de Janeiro y Montevideo. En los años 1830s, varios barcos esclavistas llegaron a Montevideo, pero pocos desembarcaron esclavos allí. La mayor parte de estos navíos ocultaban su participación en el tráfico de esclavos hacia Rio de Janeiro, ya fuera recalando en Montevideo luego de desembarcar los esclavos en la costa brasileña o antes de dirigirse a África para continuar con la trata. Este patrón de tráfico de esclavos surgió luego de la independencia de Uruguay y tras la negociación del único y posteriormente incumplido tratado anglo-brasileño contra la trata (1826), que tomó efecto en 1830. Tanto la independencia de Uruguay como el tratado contra el tráfico de esclavos eran cuestiones centrales para las relaciones diplomáticas anglo-brasileñas. De hecho, las negociaciones que dieron lugar al tratado anglo-brasileño contra la trata y las que llevaron a la creación de Uruguay como estado independiente generaron el escenario que hizo posible la ruta esclavista entre Montevideo y Rio de Janeiro durante la década de 1830.

El esquema de estos barcos esclavistas de mediados de la década de 1830 evidencia el dinamismo de la trata hacia Rio de Janeiro con escala en Montevideo y en segundo término, la introducción de esclavos africanos a Montevideo bajo el título de "colonos". Ambas operaciones estaban vinculadas a la hegemonía comercial brasileña en Montevideo. En Uruguay, el fracaso del gobierno local para aplicar las leyes vigentes contra la trata permitió el arribo de esclavos bajo el nombre de "colonos".

La política exterior británica contra el tráfico de esclavos - iniciada en 1808 al terminar Inglaterra su propia trata - enmarcó estos eventos. Inglaterra había sido el imperio atlántico que había trasladado el mayor número de esclavos en el siglo XVIII, y sólo fue superado por los luso-brasileños en la historia del tráfico de esclavos transatlántico. No obstante, desde 1808 Inglaterra promovió la abolición internacional de la trata a través de la firma de tratados con otros países y de destinar un escuadrón de la marina a la persecución de barcos esclavistas. Este nuevo arribo de africanos esclavizados también complicó las primeras relaciones diplomáticas entre Gran Bretaña y Uruguay. Mientras que la llegada de los "colonos" africanos benefició económicamente al primer gobierno del Uruguay independiente, 
este factor impidió al segundo gobierno uruguayo la obtención de un préstamo de Londres que era central para su propia subsistencia.

Desde el siglo XVII, Brasil y el Rio de la Plata tuvieron relaciones basadas en el comercio y el contrabando, en donde uno de los rubros más lucrativos fue justamente el tráfico de esclavos ${ }^{6}$. Entre 1777 y 1812, el Río de la Plata recibió al menos 60.000 desde Brasil y África ${ }^{7}$. Este comercio no solo fue importante para los rioplatenses, sino también para los brasileños y portugueses a ambos lados del Atlántico sur ${ }^{8}$. El movimiento de independencia rioplatense interrumpió el tráfico de esclavo hacia Montevideo y Buenos Aires. Después de 1810, lo que se convertiría en Uruguay se mantuvo bajo el dominio consecutivo y a veces superpuesto del régimen español, del gobierno revolucionario de Buenos Aires, del líder oriental José Artigas, y de la ocupación luso-brasileña. Este territorio experimento la guerra casi en forma continua entre 1810 y 1830, cuando se promulgó la primera constitución uruguaya. Luego de la independencia de Uruguay, las relaciones entre Montevideo y los traficantes cariocas de esclavos se continuaron bajo una nueva estructura. En el próximo apartado analizamos cómo luego de la prohibición del tráfico esclavista en Brasil, tras 1830, los traficantes brasileños crearon una nueva ruta esclavista en coordinación con sus vecinos rioplatenses.

\section{La ruta esclavista "montevideana" hacia Rio de Janeiro}

Dado que Rio de Janeiro era el puerto esclavista más importante en América, la política inglesa se centró primero en Brasil. Las discusiones entre Gran Bretaña y Brasil comenzaron desde la independencia del último

6 MOUTOUKIAS, Zakarías. Contrabando y control en el siglo XVII. Buenos Aires: CEAL, 1988; JUMAR, Fernando. Le commerce atlantique au Río de la Plata 1680-1778. Tesis (Doctorado) - École des Hautes Études en Sciences Sociales. Paris, 2000; PRADO, Fabrício. A Colônia do Sacramento: o extremo sul da América Portuguesa. Porto Alegre: Fumproarte, 2002.

7 BORUCKI, Alex. The Slave Trade to the Río de la Plata: Trans-imperial Networks and Atlantic Warfare. Colonial Latin American Review, en prensa, 2011.

8 MILLER, Joseph. Way of Death. Merchant Capitalism and the Angolan Slave Trade 1730-1830. Madison: Univ. of Wisconsin Press, p. 486 y 493-6, 1988. 
en 1822, y terminaron sólo en 1850 cuando Brasil suprimió definitivamente la trata9. Entre las medidas del tratado de 1826, se encontraba la creación de una Comisión Mixta anglo-brasileña, situada en Rio de Janeiro, que juzgaría el destino de los barcos esclavistas capturados por la armada inglesa y brasileña. Los dueños de seis barcos portugueses, capturados en 1834 y 1835, declararon en esa comisión que sus naves trasladaban "colonos" africanos a Montevideo, y no esclavos hacia Brasil. Las naves Dois de Março, Santo Antonio, Duquesa de Bragança, Aventura, Amizade Feliz, y Angelica ofrecieron esta misma explicación ${ }^{10}$. En verdad, esas naves eran parte de una operación que envolvía a Montevideo en el tráfico de esclavos.

El cónsul británico en Uruguay Thomas S. Hood, anotó el arribo de dos navíos portugueses en 1832 y 1833 que habían desembarcado esclavos en Brasil y llegaron sólo con lastre a Montevideo ${ }^{11}$. Luego, Hood anotó el arribo de otras dieciséis naves entre julio de 1834 y marzo del 1835 . Hood identificó estas naves como esclavistas pues habían llegado en lastre desde África, luego de haber desembarcado los esclavos en la costa brasileña. Estas naves tenían bandera portuguesa, pero Hood sostenía que eran brasileñas y que estaban disfrazadas para evadir la patrulla naval británica. En la tabla 1 se emplean los reportes de Hood, los libros de entrada y salida del puerto de Montevideo, así como la base de datos sobre el tráfico trasatlántico de esclavos $^{12}$, para ilustrar el desarrollo de esta ruta. Los cálculos sugieren que entre 1831 y 1839 doce por ciento de los esclavos que arribaron a Rio de Janeiro fueron conducidos a través de una ruta que empleó a Montevideo como escala. Hasta 1835, tanto la armada brasileña como la británica vigilaban la costa brasileña para capturar barcos esclavistas, pero durante los dos años siguientes el gobierno brasileño gradualmente dejó de acosar a los traficantes de esclavos, lo cual permitió el crecimiento enorme de la trata desde 1837.

9 BETHELL, Leslie. The Abolition of the Brazilian Slave Trade. Londres: Cambridge Univ. Press, 1970.

10 Irish University Press Series of British Parliamentary Papers. Slave Trade. Shannon: Irish Univ. Press, v. 14, S. 1835, Class A, p. 143-144, 148-149, 155-157, S. 1835, Class A, p. 268, y 288, 1969.

11 BNA, FO 84/141, Hood a Palmerston, febrero 10 y mayo 10 de 1833.

12 BEHRENDT, Stephen; ELTIS, David; FLORENTINO, Manolo; RICHARDSON, David. Voyages: The Transatlantic Slave Trade Database. Disponible en: <www.slavevoyages.org $>$. 
TABLA 1 - COMPARACIÓN DE VIAJES ESCLAVISTAS Y DEL ESTIMATIVO DE ESCLAVOS LLEGADOS A RÍO DE JANEIRO A TRAVÉS DE LA RUTA DE MONTEVIDEO Y DIRECTAMENTE DESDE ÁFRICA

\begin{tabular}{l|r|r|r|r|r|r}
\hline \multirow{2}{*}{ Año } & \multicolumn{2}{|c|}{$\begin{array}{c}\text { Arrivos a Rio de } \\
\text { Janeiro via } \\
\text { Montevideo }\end{array}$} & \multicolumn{2}{c|}{$\begin{array}{c}\text { Arribos a Rio de } \\
\text { Janeiro desde } \\
\text { Africa directo }\end{array}$} & \multicolumn{2}{c}{$\begin{array}{c}\text { Total de arribos a Rio } \\
\text { de Janeiro }\end{array}$} \\
\hline & Esclavos & Viajes & Esclavos & Viajes & Esclavos & \multicolumn{1}{c}{ Viajes } \\
\hline 1831 & - & - & 565 & $(1)$ & 565 & $(1)$ \\
\hline 1832 & 720 & $(2)$ & 116 & $(2)$ & 836 & $(4)$ \\
\hline 1833 & 444 & $(1)$ & 1.121 & $(3)$ & 1.565 & $(4)$ \\
\hline 1834 & 4.102 & $(11)$ & 471 & $(4)$ & 4.573 & $(15)$ \\
\hline 1835 & 5.656 & $(14)$ & 2.328 & $(10)$ & 7.984 & $(24)$ \\
\hline 1836 & 4.749 & $(12)$ & 11.319 & $(32)$ & 16.068 & $(44)$ \\
\hline 1837 & 2.829 & $(7)$ & 34.851 & $(77)$ & 37.680 & $(85)$ \\
\hline 1838 & 904 & $(2)$ & 40.899 & $(94)$ & 41.803 & $(96)$ \\
\hline 1839 & - & - & 46.914 & $(111)$ & 46.914 & $(111)$ \\
\hline Total & $\mathbf{1 9 . 4 0 4}$ & $\mathbf{( 4 9 )}$ & $\mathbf{1 3 8 . 5 8 4}$ & $\mathbf{( 3 3 4 )}$ & $\mathbf{1 5 7 . 9 8 8}$ & $\mathbf{( 3 8 3 )}$ \\
\hline
\end{tabular}

FUENTES: Voyages: The Transatlantic Slave Trade Database. Disponible en: <www.slavevoyages.org >; Archivo General de la Nación, Fondo Ex - Archivo General Administrativo (en adelante AGN-AGA), Libro 346, 1829-1835; Libro 103, 1835-1838; Libro 555, 1835-1840; Libro 373, 1841-1843.

La ruta principal de los 49 viajes esclavistas detallados en la Tabla 1 partía de Angola o Mozambique para luego desembarcar clandestinamente esclavos en la costa cercana a Rio de Janeiro pero sin entrar a ese puerto. Luego, la nave salía en lastre a Montevideo para allí ser reparada, levantar carga, y salir hacia el puerto de Rio de Janeiro, en donde declaraba como origen Montevideo y no África. En Montevideo, las naves "lavaban" su participación en la trata al levantar carga y documentación uruguaya. Esta ruta fue diseñada para ocultar el origen africano del viaje anterior a la entrada oficial de la nave al puerto de Rio de Janeiro. De entre estos 49 casos hay seis excepciones: tres barcos que partieron de Rio de Janeiro, recalaron en Montevideo y siguieron rumbo a África, y otras tres naves que llegaron a Montevideo después de desembarcar los esclavos en Brasil, y luego siguieron hacia África en lugar de retornar a Rio de Janeiro.

De estos 49 viajes esclavistas que se detuvieron en Montevideo, 40 salieron de Angola (principalmente de Luanda) y 5 de Mozambique (in- 
cluyendo a Quelimane y Lourenço Marques). Un barco declaró São Tome como puerto de origen, otros dos Cabo Verde (en donde el tráfico esclavista estaba prohibido) y otro barco no tenía procedencia africana conocida. La relación de 8 a 1 entre África Centro-Occidental y el África del Sureste en estos 49 viajes muestra un vínculo más fuerte con Angola que en los viajes que navegaban directamente entre África y Rio de Janeiro. En el tráfico directo, la relación de navíos de África Centro-Occidental con la de África del sureste llegó a un máximo de 6 a 1 en 1826, pero durante el tráfico masivo hacia Rio de Janeiro en los cuatro años siguientes esa relación se acortó a 2 a 1 en $1830^{13}$. Tal vez, la gran participación de Angola en la ruta esclavista carioca que empleaba a Montevideo como escala indica que los traficantes brasileños que operaban en Luanda fueron los responsables de la creación de este subterfugio a la legislación anti-tráfico.

La escasa información que poseemos sobre las redes comerciales detrás de estos viajes esclavistas apunta a algunos traficantes que operaban en Rio de Janeiro y a comerciantes brasileños de la plaza de Montevideo. Sólo tres capitanes aparecen en dos ocasiones en la lista de naves esclavistas que usaban a Montevideo como escala. Sólo conocemos la identidad de 27 propietarios de los barcos esclavistas, tres de los cuales eran dueños de más de un navío. Esto se corresponde con algunas características del tráfico de esclavos hacia Rio de Janeiro, en donde muchos propietarios conducían ocasionalmente viajes esclavistas, y sólo unos pocos tenían una presencia dominante en la trata antes de $1830^{14}$. La información sobre los consignatarios también aporta algunas conexiones con Rio de Janeiro y con el anterior tráfico interno entre esa plaza y Montevideo durante la dominación luso-brasileña. Conocemos la identidad del consignatario en 18 de estos viajes esclavistas, diez de los cuales fue Manuel da Costa Guimarães. Al menos hay 16 individuos con el apellido Guimarães estuvieron involucrados en el tráfico de esclavos hacia Rio de Janeiro entre 1811 y $1830^{15}$. Manuel da Costa Guimarães contrató con el gobierno uruguayo la introducción de "colonos" africanos a Uruguay en 1832. Otro consignatario

13 Disponible en: <www.slavevoyages.org $>$.

14 FLORENTINO, Manolo. Em costas negras. Uma historia do tráfico de escravos entre a África e o Rio de Janeiro (séculos XVIII e XIX). São Paulo: Companhia das Letras, 2002, p. 151.

15 Ibid., p. 205 y 255. ELTIS, David. Economic Growth and the Ending of the Transatlantic Slave Trade. New York: Oxford Univ. Press, 1987, p. 151. 
en Montevideo, Antônio Castro de Queirós, envío 141 esclavos desde Rio de Janeiro hacia Montevideo durante la ocupación brasileña a ese puerto, a mediados de los $1820 \mathrm{~s}^{16}$. Manuel Gonçalves da Costa, otro consignatario, introdujo 73 esclavos a Montevideo en 1826-7. Estos datos fragmentarios, por tanto, relacionan algunos consignatarios de los navíos de la década de 1830 con la comunidad comercial brasileña en Montevideo.

Razones geopolíticas habían llevado a los traficantes brasileños a elegir Montevideo como puerto de escala. La independencia uruguaya transformó a Montevideo en el puerto extranjero más cercano a Rio de Janeiro. En cambio, Buenos Aires no podía proveer la misma seguridad a los traficantes brasileños dada la ascendencia británica allí y la acción más energética del gobierno porteño. En marzo de 1837, el gobierno de Buenos Aires confiscó la nave brasileña Eloisa antes de su partida hacia Montevideo y África ${ }^{17}$. Su consignatario en Montevideo era Manuel Gonçalves da Costa. Luego de su arribo desde Rio de Janeiro, este barco había procedido a la construcción de escotillas adicionales. Hacia el tiempo de su partida, el Eloisa cargaba cadenas y grillos, 80 a 90 cascos vacíos para agua, pólvora, medicinas, textiles, dinero, y grandes cantidades de arroz, porotos y fariña, todo lo cual implicaba a este barco en el tráfico de esclavos. El gobierno porteño no solo confiscó a la nave, sino que prohibió a su capitán y piloto servir a bordo en naves que arribaran o partieran de Buenos Aires. Estas sanciones jamás fueron aplicadas en Montevideo a los barcos portugueses esclavistas que llegaban en lastre.

La coyuntura de los inicios de los años 1830s, cuando del gobierno brasileño aplicó una política efectiva contra la trata, permitió la creación de la ruta Montevideo-Rio de Janeiro. Una vez que las autoridades brasileñas dejaron de perseguir el tráfico, luego de 1837, esta ruta perdió razón de ser y desapareció. En 1832, el gobierno de Fructuoso Rivera firmó contratos con traficantes brasileños para trasladar a Uruguay "colonos africanos". Seis naves esclavistas capturadas por la armada británica y brasileña emplearon documentos emitidos por el gobierno uruguayo como defensa ante la Comisión Mixta de Rio de Janeiro en 1834 y 1835, por lo cual este artilugio

16 FRAGOSO, João; FERREIRA, Roberto. Tráfico de escravos e relações comerciais no Sudeste do Brasil: primeira metade do século XIX. Rio de Janeiro: Inst. de Pesquisa Econômica Aplicada - Univ. Federal de Rio de Janeiro, 2000. [Database].

17 BNA, FO 84/225, Arana a Mandeville, 29 de abril de 1837. 
fue efectivamente empleado por los traficantes esclavistas. El gobierno de Manuel Oribe, segundo presidente uruguayo, repudió esos contratos y prohibió el arribo de "colonos africanos" a Uruguay en 1835, pero nunca detuvo el arribo de barcos esclavistas en lastre a Montevideo entre 1835 y 1838. Estos hechos despertaron la preocupación británica e integraron la agenda (1833-1842) que terminó con la firma y ratificación del tratado anglo-uruguayo contra el tráfico de esclavos.

\section{El arribo de los "colonos" africanos en Montevideo}

En otra oportunidad hemos realizado apuntes sobre la demanda y aplicación de trabajo coactivo (esclavos, inmigrantes contratados, cautivos indígenas) en Buenos Aires, Montevideo y Porto Alegre en la década de $1830^{18}$. La dinamización de las economías de las ciudades-puerto y su entorno rural requirieron mayores contingentes de mano de obra, así como la fijación de un núcleo estable de trabajadores. En 1825, la Provincia Oriental prohibió el tráfico de esclavos y aprobó una ley que declaraba libres a los niños nacidos de madre esclava. Ambas medidas fueron incluidas en la constitución uruguaya de 1830 . No obstante, la prohibición de la trata era sólo declarativa, pues el gobierno debía crear procedimientos para regular casos especiales como la introducción de esclavos juntos a sus amos. Los registros de Rio de Janeiro muestran que al menos 201 esclavos fueron embarcados desde ese puerto hacia Montevideo entre 1830 y 1833, luego de la prohibición constitucional de la trata ${ }^{19}$. Aparte de una docena de casos en los cuales las autoridades uruguayas actuaron, no registros sistemáticos del arribo de esclavos en pequeños grupos entre 1830 y 1841, sólo un año antes de la abolición de la esclavitud en Montevideo ${ }^{20}$. Por otra parte, existen datos específicos sobre grandes arribos de esclavos africanos introducidos con el nombre de "colonos".

18 BORUCKI, Alex; CHAGAS, Karla; STALLA, Natalia. Esclavitud y Trabajo. Un estudio sobre los afrodescendientes en la frontera uruguaya, 1835-1855. Montevideo: Pulmón, 2004, p. 14-22.

19 Fragoso y Ferreira, op. cit.

20 Borucki, Chagas y Stalla, op. cit., p. 22-28. 
Redes políticas y comerciales entre brasileños y uruguayos facilitaron la continuidad de la trata hacia Montevideo. El primer presidente uruguayo, Fructuoso Rivera (1830-1834), había sido Comandante Militar de la campaña durante buena parte del régimen luso-brasileño. Otras figuras prominentes de ese gobierno habían sido imperiales, personalidades que habían apoyado al dominio brasileño. Tal fue el caso de Nicolás Herrera, José Ellauri, Julián Alvarez y Juan Gelly, quienes estaban casados con cuatro hijas de Lucas Obes, el Ministro de Gobierno de la administración Rivera. Estos lazos facilitaron el entendiendo entre el gobierno uruguayo y los comerciantes brasileños que introdujeron a los "colonos" africanos.

En el período colonial el tráfico de esclavos había generado ganancias a los comerciantes y entradas al fisco, lo cual era conocido por la primera administración uruguaya y sus prestamistas. Domingo Vázquez y Teodoro Vilaça realizaron préstamos al gobierno uruguayo y fueron los primeros contratistas responsables por el arribo de los "colonos africanos". Vázquez y Vilaça pagaron 30.000 pesos al gobierno a cambio de introducir 650 "colonos africanos". Los traficantes estaban autorizados a embarcar 150 africanos sobre la cuota permitida debido a la mortalidad prevista en el viaje. Los "colonos" debían trabajar 12 años para la persona que había comprado el derecho sobre su trabajo. Este tipo de contratos se asemejaba al arreglo establecido entre comerciantes locales y colonos canarios y vascos traídos a Uruguay en esos mismos años. No obstante, los precios pagados por los "colonos africanos" se asemejaban al valor de un esclavo adulto, entre 300 y 400 pesos, lo cual evidencia el fondo esclavista del asunto ${ }^{21}$. En 1834, Manuel da Costa Guimarães firmó otro contrato con el gobierno por el cual se ofrecía a pagar 42 pesos a las arcas fiscales por cada esclavo introduci$\mathrm{do}^{22}$. La tabla 2 detalla los cinco desembarcos de "colonos" africanos en Uruguay, así como los otros dos que fueron impedidos de finalizar su viaje.

Esta operación disfrazó la introducción de esclavos africanos como colonos para evadir la prohibición constitucional contra la trata y a las patrullas navales británicas. En Montevideo, la Policía abrió un registro con el nombre de cada "colono" y su patrón. Este era el único documento oficial que refería a los africanos en su condición de "colonos". En ese

21 El Estandarte Nacional, Montevideo, n. 14, enero 26 de 1835, p. 3.

22 PIVEL DEVOTO, Juan. Prologo. In: BAUZÁ, Francisco. Estudios sociales y económicos. Montevideo: Colección Clásicos Uruguayos, p. XVII-XVIII, 1972. 
registro sólo se anotaron 220 individuos, pues la mayoría de los africanos fueron simplemente vendidos como esclavos ${ }^{23}$. Menos de la quinta parte de los africanos desembarcados fueron sujetos al sistema de colonato, lo cual demuestra el carácter esclavista de la operación.

TABLA 2 - NAVÍOS DIRIGIDOS HACIA URUGUAY CON “COLONOS AFRICANOS”, 1833-1835

\begin{tabular}{|c|c|c|c|c|}
\hline Fecha & Nave & $\begin{array}{c}\text { Lugar de } \\
\text { desembarco }\end{array}$ & $\begin{array}{l}\text { Número de } \\
\text { africanos } \\
\text { desembar- } \\
\text { cados }\end{array}$ & Agentes \\
\hline $25 / 10 / 1833$ & Aguila I & $\begin{array}{l}\text { Montevideo } \\
\text { (Santa Lucía) }\end{array}$ & 239 & Platero \\
\hline $14 / 02 / 1834$ & Rio de la Plata & Maldonado & $* 450$ & Vázquez y Vilaça \\
\hline $04 / 04 / 1834$ & Porfia & Montevideo & $* 300$ & Vázquez y Vilaça \\
\hline $28 / 12 / 1834$ & Río de la Plata & $\begin{array}{l}\text { Capturado por } \\
\text { la armada britá- } \\
\text { nica y llevado a } \\
\text { Rio de Janeiro }\end{array}$ & - & Vázquez y Vilaça \\
\hline $30 / 01 / 1835$ & $\begin{array}{l}\text { Esperanza } \\
\text { Oriental }\end{array}$ & $\begin{array}{l}\text { Montevideo } \\
\text { (Buceo) }\end{array}$ & 350 & Guimarães \\
\hline $16 / 03 / 1835$ & Delfina & Maldonado & 251 & Vázquez y Vilaça \\
\hline $13 / 06 / 1835$ & $\begin{array}{l}\text { Paquete Africano } \\
\text { (a) Cesar Augusto }\end{array}$ & $\begin{array}{l}\text { El gobierno no } \\
\text { permitió de- } \\
\text { sembarco, salió } \\
\text { al Brasil } \\
\end{array}$ & - & Guimarães \\
\hline Total & & & 1590 & \\
\hline
\end{tabular}

NOTAS: *Hood señaló que 450 y 300 africanos fueron desembarcados por el Río de la Plata y por el Porfia, mientras que los registros de la policía muestran sólo 336 y 164. IUP, v. 14, S. 1836, Class B, p. 82-83 y 149.

FUENTES: Díaz de Guerra, p. 40-44; AGN-AGA, Libro 938, Policía de Montevideo, Libro de Africanos introducidos en el país 1833-1835; El Universal, Montevideo, n. 1260, Noviembre 2 de 1833, p. 3; El Estandarte Nacional, Montevideo, n. 21, Febrero 4 de 1835, p. 3; El Nacional, Montevideo, Junio 13 de 1835, p. 2.

23 AGN-AGA, Libro 938, Policía de Montevideo, Libro de Africanos introducidos en el país 1833-1835. 
El viaje de Montevideo a la costa africana, incluyendo la provisión de africanos y el retorno, podía llevar 7 meses. El 3 de agosto de 1833 partió hacia Angola el bergantín Río de la Plata, sólo con lastre ${ }^{24}$. Aunque debía desembarcar en la capital uruguaya, el navío arribó a Maldonado el 14 de febrero de 1834. Trasladaba 336 “colonos", 40 libras de carey y 200 cocos de bálsamo ${ }^{25}$. La escala en Maldonado se debió al aprovisionamiento de víveres, pero también fue provocada por la revuelta de algunos marineros. La insurrección fue reprimida, tras lo cual los africanos fueron desembarcados.

En Maldonado fueron vendidos los derechos de patronato de 209 africanos del patacho Delfina, otros cinco fueron entregados a los oficiales encargados del operativo. Por último, 37 fallecieron de enfermedades y por efecto del clima tras el desembarco ${ }^{26}$. Sobre las condiciones en que viajaban los africanos del Esperanza Oriental la prensa advirtió que: “[...] han llegado a nuestras playas cargados de cadenas, que ocho ú diez han muerto en el viaje y que sesenta se han ahogado al desembarcarlos por causa del mal tiempo y sobre todo de la torpeza de sus conductores"27.

Es posible hallar referencias consistentes sobre las edades de los “colonos" africanos de Montevideo. El primer embarque consistía en 239 niños y jóvenes, habiendo sido contabilizados por la policía sólo 141. El resto había sido vendido antes de la llegada de las autoridades. Casi el 90\% de los africanos registrados por la policía no alcanzaba los 10 años de edad. El $56 \%$ era de sexo masculino y el $44 \%$ del femenino. Las tablas 3 y 4 evidencia la presencia abrumadora de niños en dos de estos navíos esclavistas.

Los recibos de traspaso del patronato que transcribió Díaz de Guerra de los africanos llevados por el Río de la Plata a Maldonado en 1834, corresponden a menores de 9 años, e incluso a un "colono" que tenía 5 años ${ }^{28}$. En el caso del Delfina, el $72 \%$ de los africanos eran del sexo masculino y el $28 \%$ del femenino, lo cual superaba la cuota máxima de varones estipulada. No obstante, se debe advertir que este grupo constituía sólo el $77 \%$ del total de africanos desembarcados en esa ocasión.

24 AGN-AGA, Ministerio de Guerra, Caja 1818, Agosto de 1833 [Pasaporte del Río de la Plata], 3 de agosto de 1833 .

25 DÍAZ DE GUERRA, María A. Documentación relativa a esclavos del Departamento de Maldonado. Montevideo: IMCO, p. 40, 1983. La autora señala 338 africanos.

26 Ibid., p. 44.

27 El Estandarte Nacional, Montevideo, 3 de febrero de 1835, p. 2.

28 Díaz de Guerra, op. cit., p. 42-43. 
TABLA 3 - EDAD Y SEXO DE 141 AFRICANOS DESEMBARCADOS POR EL $A ́ G U I$ LA I (1833)

\begin{tabular}{l|c|c}
\hline \multicolumn{1}{|c|}{$\backslash$ Edad } & De 8 a 9 años & De 14 a 18 años \\
Sexo & 56 & 6 \\
\hline Femenino & 68 & 11 \\
\hline Masculino &
\end{tabular}

NOTA: Uno de los africanos de mayor edad murió luego del desembarque.

FUENTE: AGN-AGA, Ministerio de Gobierno, Caja 848, Noviembre de 1833, [Relación de 141 de los 239 africanos desembarcados en Santa Lucía] 2 de noviembre de 1833.

TABLA 4 - EDAD Y SEXO DE 194 AFRICANOS DESEMBARCADOS POR EL DELFINA (1835)

\begin{tabular}{l|c|c|c}
\hline \multicolumn{1}{|c|}{$\backslash$ Edad } & De 4 a 7 años & De 8 a 11 años & Mayores de 12 años \\
\hline Sexo & 18 & 25 & 12 \\
\hline Memenino & 76 & 58 & 5 \\
\hline
\end{tabular}

FUENTE: DÍAZ DE GUERRA, María. Op. cit., p. 44.

Las fuentes británicas confirman la enorme presencia de africanos muy jóvenes entre los africanos embarcados como "colonos" hacia Montevideo. En 1834, Thomas S. Hood reportó sobre el desembarque del navío Porfia que: "Estos esclavos, principalmente niños, fueron abiertamente llevados a tierra, y ahora están en exhibición pública para la venta en un mercado establecido a las puertas de la ciudad" ${ }^{29}$. Al año siguiente, Hood describió a los africanos traídos por el navío Esperanza Oriental como: "principalmente niños de ocho a doce años de edad"30. Los africanos del último viaje del Río de la Plata, capturado por la marina inglesa, eran mayoritariamente niños: 269 niños y 179 niñas, o el 85 por ciento de los 522 africanos sobrevivientes ${ }^{31}$. La alta proporción de niños en estos navíos esclavistas corresponde con la tendencia del último período del tráfico esclavos hacia Cuba y Brasil, cuando los niños y los hombres adultos predominaban. Los niños africanos estuvieron más involucrados en el último periodo - el ilegal - del tráfico de esclavos hacia Rio de Janeiro que hacia

29 IUP, v. 14, Sessions 1835, Class B, 83.

30 BNA, FO 84/182, Hood to Wellington, 16 feb. 1835.

31 IUP, v. 23, Sessions 1843, Class B, 475. La lista incluye 94 hombres. 
cualquier otra región del mundo atlántico, y el caso de los "colonos" africanos de Montevideo es consistente con esta tendencia ${ }^{32}$.

Este ensayo no intenta esclarecer los debates sobre la significativa participación de niños en los navíos esclavistas durante el siglo XIX, pero la evidencia de los "colonos" africanos de Montevideo puede ayudarnos a ilustrar algunos puntos ${ }^{33}$. Parte del debate se centra en dilucidar si fueron causas originadas en África o en las Américas las que llevaron a este incremento en niños esclavizados embarcados. Si el tráfico transatlántico de esclavos tenía una correspondencia directa con el tráfico interno africano de esclavos, entonces debemos buscar las razones de este cambio en África. No obstante, eventos en el Nuevo Mundo tales como la prohibición y continuación ilegal del tráfico, pudieron haber contribuido a este aumento de niños embarcados hacia las Américas.

Paul Lovejoy recientemente ha revisado la literatura sobre los niños y el tráfico de esclavos, centrándose en el Golfo de Benín ${ }^{34}$. Lovejoy revela algunos casos en que naves esclavistas embarcaron únicamente mujeres y niños justo antes del inicio del siglo XIX. Sobre esa centuria, Lovejoy especula que el trabajo en las plantaciones cafetaleras brasileñas puede haber llevado a este incremento de niños en el tráfico transatlántico pues los niños podían ser empleados para recoger granos de café. Asimismo, eventos en el Nuevo Mundo pudieron haber ocurrido justo al mismo tiempo que causas en África llevaron a este aumento de la presencia de niños en las embarcaciones esclavistas. Las patrullas británicas anti-esclavistas en el Atlántico llevaron a los traficantes de esclavos a probar nuevas tácticas vinculadas a la compra, el crédito y la venta de esclavos. Lovejoy sugiere que embarcar más niños en la nave esclavista permitía una mayor carga de esclavos dentro de la nave y disminuía los costos de controlar los esclavos

32 KARASCH, Mary. Slave Life in Rio de Janeiro, 1808-1850. Princeton: Princeton Univ. Press, 1987. Ver: ELTIS, David. Fluctuations in the Age and Sex Ratios of Slaves in the Nineteenth-Century Transatlantic Slave Traffic. Slavery \& Abolition, v. 7, n. 1, p. 257-272, 1986; ELTIS, David; ENGERMAN, Stanley. Was the Slave Trade Dominated by Men? Journal of Interdisciplinary History, v. 23, n. 2, p. $237-$ 257, 1992; y Fluctuations in Sex and Age Ratios in the Transatlantic Slave Trade, 1663-1864. Economic History Review, v. 46, n. 2, p. 308-323, 1993.

33 Ver el dossier "Children in European Systems of Slavery", de la revista Slavery \& Abolition de agosto de 2006.

34 LOVEJOY, Paul. The Children of Slavery - The Transatlantic phase. Slavery \& Abolition, v. 27, n. 2, p. 197-217, aug. 2006. 
a bordo ${ }^{35}$. Debemos señalar que esta estrategia de comprar todos los esclavos que se pudiera en el menor tiempo posible puede haber llevado al incremento de niños en estos navíos esclavistas en tanto hubiera mercados disponibles en la costa africana que permitieran esta escala y rapidez en la operativa de carga de esclavos.

Los registros de una de las naves que embarcó "colonos" africanos ilustran los procedimientos y tiempo de la compra de esclavos en la costa angolana. Antes de su captura por la marina inglesa, el bergantín Río de la Plata había embarcado 552 africanos esclavizados. Los traficantes brasileños a cargo de esa operación habían comprado 74 esclavos en Benguela, 35 en Novo Redondo, 100 en Luanda, y 343 en Ambriz. Estos traficantes comenzaron la compra de esclavos hacia fines de agosto de 1834, y la terminaron sólo hacia fines de noviembre de ese año ${ }^{36}$. Las actividades de estos traficantes no presentan apuro alguno, pues ellos se detuvieron en cuatro puertos de la Angola portuguesa para embarcar en el bergantín una carga muy grande de africanos esclavizados. No resulta claro si el ritmo lento de compras de esclavos fue una característica o una anomalía del tráfico angolano de esclavos en este período. David Eltis y Stanley Engerman señalan que el aumento de la presencia de niños en las naves esclavistas fue particularmente pronunciado en África Centro-Occidental, que fue la región principal que suministraba esclavos a Rio de Janeiro y sus puertos de cercanías ${ }^{37}$. Una muestra mayor de estudios de caso sobre el tráfico angolano del siglo XIX es esencial para poder resolver este dilema.

Tanto la participación británica como la iniciativa uruguaya terminaron con este breve resurgimiento del tráfico de esclavos a gran escala. Las dos últimas naves que intentaron desembarcar esclavos no tuvieron éxito. Mientras que la armada británica detuvo al bergantín Río de la Plata y lo envió ante la Comisión Mixta de Rio de Janeiro, el gobierno de Oribe no permitió el desembarco de los africanos arribados en el Paquete Africano (a) Cesar Augusto. Luego de unos días, este barco partió hacia Brasil debido a la imposibilidad de vender sus esclavos en Montevideo y ante noticias de que una nave inglesa había sido enviada desde Buenos Aires para detener-

35 Ibid., p. 207.

36 Arquivo do Palácio de Itamarati, Rio de Janeiro, Lata 28, Maço 1, Pasta 2, Río de la Plata. Lista de compra de esclavos, Agosto 24, 1834.

37 ELTIS, D.; ENGERMAN, S. Fluctuations in Sex and Age Ratios in the Transatlantic Slave Trade, 1663-1864. Economic History Review, v. 46, n. 2, p. 308-323, 1993. 
$1 a^{38}$. Aunque en 1835 el gobierno detuvo definitivamente el desembarco de esclavos africanos como "colonos", la cuestión del tráfico de esclavos estaría en la agenda de Uruguay y Gran Bretaña durante los próximos siete años.

Las fuentes inglesas evidencian la resistencia de las autoridades uruguayas a firmar un tratado con Gran Bretaña contra la trata desde 1835 en adelante ${ }^{39}$. Ese tratado fue firmado en 1839 y ratificado en 1842. En ambas instancias una coyuntura apremiante en el Río de la Plata obligó al gobierno de Rivera a ceder ante la presión británica. Entre 1835 y 1842, tanto el gobierno de Oribe como el de Rivera intentaron obtener una compensación económica a cambio de la firma del tratado y su ratificación. Esto no era excepcional, dado que Gran Bretaña había pagado 12 millones de libras a los propietarios de esclavos tras la abolición de la esclavitud en sus colonias del Caribe en 1837. Asimismo, algunas de las primeras notas sobre el Uruguay independiente en el Times de Londres versaron sobre la continuidad del tráfico de esclavos en ese país ${ }^{40}$. El tratado anti-tráfico era esencial para la política comercial británica dado que Inglaterra, por su propia legislación, estaba imposibilitada para firmar un tratado comercial con un país que previamente no hubiese firmado un tratado bilateral contra la trata. En 1842, se firmó el primer tratado anglo-uruguayo de comercio, pocos meses después de que el tratado anti-tráfico de esclavos entre Uruguay e Inglaterra fuera ratificado por las cámaras uruguayas.

\section{El debate político sobre los "colonos" africanos}

En Montevideo, las primeras noticias sobre los "colonos" africanos se conocieron en noviembre de 1833, pero los debates sobre su situación recién habrían de surgir en 1835. El 25 octubre de 1833 a la medianoche fueron desembarcados los africanos del Águila I en la barra del Río Santa

38 IUP, v. 14, S. 1836, Class B, 149.

39 El archivo del Foreign Office conserva documentos relativos al tráfico de esclavos en varios países. Allí he consultado el material sobre Uruguay para los años 1830-1843. BNA, FO84/141, 160, 182, 206, 225, 259, 294, 330, 375, 417, 482 .

40 The Times, Londres, n. 15931, Octubre 27 de 1835, p. 2; n. 15935, Octubre 31 de 1835 , p. 1 . 
Lucía. El comisario Pablo Ordóñez tomó conocimiento el día 30, sorprendiendo esa misma jornada a Francisco Ylla, que los estaba vendiendo en las cercanías del Arroyo Pantanoso. Allí el comisario decomisó a 136 africa$\operatorname{nos}^{41}$. Ordóñez afirmó que: "Los 103 esclavos restantes han sido vendidos, como tales, a varios; uno de los compradores ha sido D. José Lapuente, que tiene un matadero en el Pantanoso, el cual ha comprado 8 a 200 pesos cada uno. Nada hay de patronato" ${ }^{\prime 2}$. El comisario, luego de pasar el caso al Juez del Crimen, envió una nota a El Universal. Otras denuncias se publicaron hasta que el gobierno ofreció una explicación.

El contrato entre el Estado y los particulares no fue publicado, pues aún estaba a estudio de la Asamblea General. Ese pretexto fue empleado por el gobierno para mantenerlo en reserva. A pesar de carecer de ratificación legislativa, los efectos del contrato fueron cumplidos. La policía debía tomar razón de los africanos del Águila I como procedentes de ese contrato, interviniendo en el traspaso de los derechos de patronato. El documento de "venta" expresaría los años de servicio que debía prestar el "colono", así como que su situación y la de su tutor quedaban sujetas a una resolución, que habría de sancionar el Poder Legislativo. De este modo, la policía debía formar un registro de los traspasos de patronato, especificando el nombre y vecindario de cada tutor. Toda acción de compra en la que no interviniese la policía sería anulada ${ }^{43}$. El libro de "colonos africanos" de la Jefatura Política y de Policía de Montevideo sólo registra 220 asientos, habiendo sido fechado el último el 19 de marzo de $1835^{44}$. A la capital arribaron al menos 753 africanos bajo este sistema, lo cual demuestra la dimensión de la evasión, como lo señalamos más arriba ${ }^{45}$.

En enero de 1835 comenzó una campaña del periódico El Estandarte Nacional contra de la introducción de los "colonos" africanos. Algunos

41 En el documento de devolución de los africanos al vendedor, firmado por Ordóñez e Ylla el día 2 de noviembre, figura la cifra de 141 africanos. Probablemente Ordóñez encontró otros cinco africanos luego de decomisarle los 136 a Ylla. AGN-AGA, Ministerio de Gobierno, Caja 848, Noviembre de 1833, [Relación de 141 de los 239 africanos desembarcados en Santa Lucía], 2 de noviembre de 1833.

42 El Universal, Montevideo, n. 1260, 2 de noviembre de 1833, p. 3, correspondencia de Pablo Ordóñez.

43 El Universal, Montevideo, n. 1264, 7 noviembre de 1833, p. 3.

44 AGN-AGA, Libro 938, Policía de Montevideo, Libro de Africanos introducidos en el país $1833-1835$.

45 Algunos "colonos" fueron vendidos en el litoral. En 1835 se tenía noticias de que algunos africanos del Esperanza Oriental habían sido trasladados a Paysandú. El Estandarte Nacional, Montevideo, 12 de febrero de 1835 , p. 2. 
lectores se identificaron como "Los secretarios de los reyes africanos" o "El Rey negro Constitucional" al enviar cartas denunciando esta situación. Detrás de esos seudónimos estaba el grupo vinculado a Bernardo P. Berro y Carlos Villademoros, quienes ejercerían cargos de importancia durante el gobierno de Oribe. Un corresponsal denominado "Un ciudadano" expresó sobre el contrato de "colonos" que:

Es ciertamente doloroso que no se haya elevado del seno de nuestra Representación ninguna voz contra ese escandaloso convenio. Centenares de negros y aun pudiéramos decir millares, se han introducido desde entonces y se han vendido públicamente. Pero lo más odioso de este asunto es la apariencia de legalidad y filantropía que los interesados en este tráfico quieren darle ¿a quién engaña ese título de colonos con que se introducen? Pues que ¿no se sabe que a pesar del zelo de la policía los mas de ellos son vendidos absoluta y perpetuamente? ${ }^{46}$

$\mathrm{Al}$ autor le sorprendió el manto de legalidad con que se pretendía cubrir la operación. Al día siguiente "El Rey negro Constitucional" denunció que los "colonos" eran vendidos por sumas de entre 300 y 450 pesos, lo cual constituía un doble engaño, pues se vendían los "colonos" como esclavos y por un precio mucho mayor que el declarado en el documento de venta, que era de 200 pesos. Algunos notarios suministraban papel sellado de años anteriores, con lo cual la operación de venta parecía haberse realizado en tiempos en que la introducción de esclavos era legal, bajo el dominio brasileño, quedando el fraude completado ${ }^{47}$. En su siguiente nota, "Un Ciudadano" señaló que el bergantín Río de la Plata había sido interceptado por la marina inglesa. El buque poseía una tripulación que poco más de una docena de hombres, pero trasladaba 500 niños africanos a Montevideo ${ }^{48}$. De haber llegado a su destino, ese habría sido el mayor contingente de africanos traídos forzadamente durante la década de 1830.

El 3 de febrero de 1835 El Estandarte Nacional inició la publicación de una serie de artículos editoriales sobre los "colonos" africanos, que se 
extendió hasta marzo debido al arribo del patacho Delfina. El primer artículo atendió a la polémica sobre la liquidación del tráfico en el hemisferio norte. En particular, se detuvo en la situación de la revolución norteamericana, que si bien había proclamado la independencia fue omisa ante la libertad de los esclavos. El editor citó un texto del inglés Edward Ruston sobre esa circunstancia: “[...] justificais vuestra revolucion por el derecho natural de la libertad, pero los esclavos negros os oponen el mismo argumento y este es sin réplica: ¿tan quisquillosos en puntos de vuestros derechos, como podeis olvidaros de los suyos"49. Cabía a los lectores extrapolar esa situación a Uruguay, en donde se estimaba a Estados Unidos como modelo de libertad republicana. En este debate se señaló la situación norteamericana en varias ocasiones, tanto por quienes denunciaban la corrupción local como por quienes defendían la legalidad del arribo de "colonos" africanos ${ }^{50}$.

El contrato entre el Estado y los primeros introductores fue inicialmente publicado por El Estandarte Nacional. El redactor señaló que los africanos que había traído Costa Guimaraens no estaban amparados por ese acuerdo, siendo su situación completamente ilegal. Por otra parte, se presentó un extracto de la vista fiscal de Lucas Obes favorable al contrato con Vázquez y Vilaça. Allí figuró una frase - que habría de hacerse célebre - sobre la utilidad y la legalidad:

[...] no habiendo ley que se oponga a la propuesta y si razones de interés político que abogan por su aprobación, el fiscal tiene por inútil detenerse en enumerar todas las ventajas que promete al exausto Erario de la República el pronto y seguro percivo de treinta mil pesos, aunque la historia de todos los tiempos nos enseñe que la UTILIDAD para las naciones cultas, es un sinónimo de lo LICITO, y que a no ser apoyadas en esta regla jamás hubieran pensado en comerciar hombres negros cuando tenían Colonias ${ }^{51}$.

Lucas Obes no percibió que la Constitución fuera un impedimento para la celebración de un contrato que habilitaba veladamente la trata.

\footnotetext{
49 El Estandarte Nacional, Montevideo, n. 20, 3 de febrero de 1835, p. 2.

50 Ver entre otros artículos: El Estandarte Nacional, Montevideo, n. 24, 7 de febrero 1835, p. 3 .

51 El Estandarte Nacional, Montevideo, n. 21, 4 de febrero 1835, p. 2.
} 
Igualmente, consideró que el beneficio económico había impulsado a Gran Bretaña a perseguir la trata transoceánica. Sala y Alonso señalaron que en Lucas Obes se combinaban sin contradicciones aparentes la impronta del progresismo ilustrado con la mentalidad esclavista, lo cual era representativo de la elite montevideana ${ }^{52}$. Se debe advertir que la moral utilitarista del enciclopedismo impregnó a un sector importante de las clases letradas durante el proceso revolucionario ${ }^{53}$. Luego de la independencia uruguaya, la prédica liberal de los sectores altos no tenía mayores perplejidades en incluir a la esclavitud entre las propuestas para impulsar la actividad económica, lo cual se enfrentaba al discurso republicano emergente de la última guerra. Pero aún quienes defendían los derechos de los africanos estaban impregnados de una actitud discriminatoria hacia ellos. El mismo editorial que había denunciado la situación de los "colonos" del Esperanza Oriental, su encierro a las afueras de la ciudad y sus padecimientos, también ironizó sobre la propuesta de un diario de Buenos Aires, de llamar al Cerro de Montevideo "Villa Angola", sosteniendo que Uruguay debía cambiar su nombre por "República de Angola":

[...] porque a la verdad tal afluencia de colonos negros que aborda todos los dias nuestras playas, y se difunde por todos los ángulos de nuestro territorio, que dentro de poco la población será casi del todo negra, y el extranjero que desembarque gozará del gracioso espectáculo que presentara nuestra ilustrada capital con tanta cara negra contrastando con la blancura exterior de sus edificios ${ }^{54}$.

El temor racista fue empleado por quienes se oponían a la introducción de africanos, quienes no obstante se interesaban por mejorar la situación

52 SALA, Lucía; ALONSO, Rosa. El Uruguay comercial, pastoril y caudillesco, Montevideo, E.B.O., 1989. T.II, p. 171.

53 CHIARAMONTE, José. C. La crítica ilustrada de la realidad. Economía y sociedad en el pensamiento argentino e iberoamericano del siglo XVIII. Buenos Aires: CEAL, p. 94-95, 1994. El caso de Lucas Obes era excepcional, pues en 1821 había defendido a dos esclavas que habían dado muerte a su ama. El caso de Celedonia Wich había conmovido a los habitantes de Montevideo, dada la notoriedad de la víctima, la crueldad que ejercía sobre sus esclavas, y el hecho de que éstas la hubieran asesinado. BARRIOS PINTOS, Aníbal. Historias privadas de la esclavitud. In: BARRÁN, José P.; CAETANO, Gerardo; PORZECANSKI, Teresa (Dirs.). Historias de la vida privada en el Uruguay. Entre la honra y el desorden 1780-1870. Montevideo: Taurus, T.1, p. 184, 1996.

54 El Estandarte Nacional, Montevideo, n. 21, 4 de febrero 1835, p. 3. 
de los africanos en Uruguay, tratando de aliviar una circunstancia negativa. El Estandarte Nacional se concentró en los días siguientes en despejar los problemas legales en torno a la situación de los "colonos" africanos y de su arribo. Este diario evidenció la diferencia entre la condición de colono y la de esclavo, sosteniendo que los africanos no habían partido voluntariamente de su tierra, sino que habían sido esclavizados por sus congéneres y comprados por negociantes ${ }^{55}$. La libertad era requisito para suscribir un contrato y los africanos traídos al Uruguay indudablemente carecían de ella. De este modo, los contratos de "colonos" que hipotéticamente se rubricaron eran totalmente ilegales.

La prensa también señaló que la infracción del gobierno uruguayo a las disposiciones de la Constitución contra la trata, podían ser utilizadas por los países garantes de la independencia (Argentina, Brasil e Inglaterra) para negar su reconocimiento definitivo. Luego de haber pasado cinco años de la Jura de la Constitución esos países debían proceder al reconocimiento definitivo de Uruguay ${ }^{56}$. Esta situación no carecía de verosimilitud. En esos días la prensa difundió que el Ministerio de Negocios Extranjeros de Brasil había pasado una nota a su consulado en Montevideo, para recabar información sobre el tráfico de esclavos, demandando que si eran ciertas las noticias que habían llegado a Rio de Janeiro, se protestase ante el gobierno uruguayo y se exigiese la firma de un tratado para prohibir la trata ${ }^{57}$. La temida intervención brasileña también sobrevoló este asunto. Asimismo, se advirtió que Uruguay era la única república en el continente que aún continuaba practicando el tráfico africano.

La prensa también publicó en sucesivas entregas la propuesta que Vázquez y Vilaça habían realizado al gobierno, así como la vista de Lucas Obes. Los editores criticaron ambos escritos. Obes señaló que: "Es preciso... que la población se multiplique, que los consumos se agranden, que las necesidades adquieran todo su imperio, que la falsa caridad desaparezca y que el orgullo heredado pierda su fuerza, para que la clase proletaria entre sin violencia a ocupar el puesto de los esclavos" ${ }^{\prime 58}$. Sin embargo, la inmi-

55 El Estandarte Nacional, Montevideo, n. 23, 6 de febrero 1835, p. 2.

56 El Estandarte Nacional, Montevideo, n. 22, 5 de febrero 1835, p. 2.

57 El Estandarte Nacional, Montevideo, 9 de febrero 1835, p. 3, correspondencia "Unos ciudadanos".

58 El Estandarte Nacional, Montevideo, 13 de febrero 1835, p. 2, Vista Fiscal de Lucas Obes. 
gración no arribaba en las cifras deseadas, la población del Uruguay no era numerosa y no se sujetaba fácilmente al trabajo. A partir de esos supuestos era conveniente el ingreso de "colonos" africanos. En el pasado reciente se habían firmado contratos para el arribo de pobladores vascos y canarios, ¿qué impedía aceptar contratos de inmigración con "colonos" africanos? El fiscal también opinó sobre el origen del tráfico de esclavos y la continuidad de la esclavitud en las repúblicas latinoamericanas:

Aquel comercio justamente proscripto por las naciones mas ilustradas puede considerarse como una plaga con que ellas mismas infectaron la América en un principio, y que perpetuada por la activa codicia de todos los pueblos comerciantes, llegó a ser para nosotros lo que ciertos males que la medicina se ve obligada a respetar temerosa de causar otros mayores con su improvisada curación.

Según el fiscal, la esclavitud constituía un resabio del período colonial que había sido introducido por las potencias europeas cuando a éstas les reportaba utilidad. Al alterarse la situación del continente, tras la independencia de los Estados Unidos, Inglaterra persiguió el tráfico de esclavos pues ya no le causaba ningún beneficio. Lucas Obes vinculó su discurso sobre el progreso económico y la soberanía nacional a la vista favorable a la introducción de africanos.

Tendremos lo que gozamos y seremos contribuyentes perpetuos de aquella potencia que nos suministra desde la legumbre y los lacticinios para la mesa, hasta el tejido que ha de cubrir nuestra cama; y desde la azada que ha de romper la tierra hasta el alfiler que ha de clavarse en el tocado de nuestras damas. ¿Por ventura es independiente el pueblo que en tantas y tan variadas necesidades no depende de si mismo y de sus brazos? El Fiscal General, así discurriendo, ha llegado a persuadirse que entre los grandes absurdos a que hemos sido arrastrados por el espiritu de imitación servil y vestigio revolucionario, uno sin medida fue esa ley que cerró la entrada al comercio de esclavos; pero una vez existente la prohibición, nada mas grato que respetarla. 
Obes consideró que el cese del tráfico esclavista fue una acción perjudicial para el país, no teniendo reparo en sostener esa opinión. Se hace difícil pensar en un bando de tono nacionalista-esclavista contra uno abolicionista-extranjerizante en Uruguay. No obstante, ese escenario fue instalado por quienes defendían la perpetuación de la esclavitud en las repúblicas de América Latina. La prédica de Obes no sólo manifiesta la capacidad de mutación de los argumentos esclavistas en el siglo XIX, sino también la importancia que las elites aún asignaban a la esclavitud como práctica generadora de riqueza. Contra esos asertos el editorialista de $E l$ Estandarte Nacional consideró que: "No es solo la supresión del comercio de esclavos [lo] que vitupera el Sr. Fiscal, este acto de liberalismo de los hombres de la revolución no sea tal vez, el que mas ha dolido ha nuestro aristocrático magistrado". El apunte estaba dirigido a la activa colaboración de Obes con el régimen luso-brasileño, hacía referencia a la división entre los "imperiales" y "patriotas" durante el inicio de vida independiente de Uruguay.

En febrero de 1835, la Comisión Permanente del Poder Legislativo exigió al gobierno la suspensión de la venta de los "colonos", lo cual no fue acatado. En marzo, tras la asunción del nuevo gobierno, se inició el trámite legislativo del tema. El diputado Alejandro Chucarro no creía que los africanos introducidos fueran esclavos, pues consideró legítima su condición de "colonos". Bernardo P. Berro escribió una extensa nota con el seudónimo "Un imparcial" en El Estandarte Nacional, ironizando sobre la opinión de Chucarro.

Supongamos que el honorable Sr. diputado, llevado de su selo patriótico por el fomento de nuestra industria [e] imposibilitado de tomar creces a falta de población proletaria se marcha a Londres, y allá compra a los ladrones centenares de inglesitos y vuelve con ellos al puerto de Montevideo diciendo que son colonos por que el Gobierno ha estipulado con él que les de libertad después que los introduzca. No hay que arquear las cejas y escandalizarse [...] ¿Qué tiene que ver el color o la barbarie con los derechos de naturaleza y con las determinaciones de justicia? ${ }^{59}$

59 El Estandarte Nacional, Montevideo, n. 45, 10 de marzo 1835, p. 2, correspondencia "Un imparcial". 
Este fragmento es uno de los pocos en el que se denunció la edad de los "colonos" como otro rasgo de la iniquidad de la operación. Berro expresó que no se podía fundamentar en cuestiones de "color" o cultura la sujeción de los africanos a la condición de "colonos", pues era tan criminal el secuestro de niños ingleses como el de africanos. En varias ocasiones los defensores de esta operación señalaron que los "colonos" vivirían más a gusto en una cultura civilizada como en Uruguay que en sus sociedades nativas. Esta nota le valió a Berro un juicio de imprenta iniciado por Chucarro.

Otras expresiones, como la poesía, fueron empleadas para denunciar la trata. El propio Bernardo P. Berro remitió una composición a El Estandarte Nacional, con el seudónimo "Un republicano escandalizado"60. En esa línea se situó La madre africana, de Francisco Acuña de Figueroa, publicada en El Universal. Esta pieza se difundió en forma simultánea al debate sobre los "colonos" africanos, durante el gobierno de Oribe, y al día siguiente de haberse conocido en Montevideo el arribo del Delfina. Si bien Acuña de Figueroa aprovechó esta oportunidad, se debe advertir que en otras ocasiones denunció situaciones vinculadas al tráfico y a la población negra, lo cual era inusual para los escritores de esa época ${ }^{61}$. La introducción de La madre africana situaba a la poesía en el debate:

Mi intención es solo pintar con los colores de la poesía (si tal modo me es dado) los efectos, la desolación y los sentimientos

60 El Estandarte Nacional, Montevideo, n. 22, 5 de febrero de 1835, p. 3, correspondencia “Un patriota escandalizado". BASSAGODA, Roger. Don Bernardo P. Berro poeta. Dos poesías desconocidas y otros comentarios. Revista Nacional, Montevideo, año VII, tomo XXV, n. 73, enero de 1944.

61 El tratamiento de este tema por Acuña de Figueroa merece un estudio aparte. ACUÑA DE FIGUEROA, Francisco. Nuevo Mosaico Poético. Montevideo: Claudio García, 1944, p. 33, 90 y 113, entre otras. Además de La madre africana, el poeta compuso A la negrita Remedios y tradujo el salmo Super Flumina Babilonis, referido a la esclavitud de los judíos en Babilonia, que podía extrapolarse a la condición de los africanos en Montevideo dado su contexto. En las poesías A Juan Copete y Los decretos pilatunos, Acuña de Figueroa incluyó denuncias contra el tráfico de esclavos y el resguardo que los brasileños hacían de sus esclavos durante el inicio de la Guerra Grande. En Sáficos y adónicos. A la memoria de la excelente niña dona Mercedes Antuña y del joven poeta don Adolfo Berro, Acuña de Figueroa señaló la vocación de Adolfo Berro con relación a la libertad de los esclavos. También de su autoría, el Canto patriótico de los negros (1834), que fue escrito en lengua bozal, constituye un homenaje a la ley de libertad de vientres en donde los negros aparecen festejando la libertad declarada para sus hijos. Allí figuró por primera vez en la prensa el vocablo candombe. Para un análisis de esa composición como simulacro del habla de los negros ver GORTÁZAR, Alejandro. Del aullido a la escritura. Voces negras en el imaginario nacional En: ACHUGAR, Hugo (Coord.). Derechos de memoria. Nación e independencia en América Latina, Montevideo, FHCE, p. 221-225, 2003. Gortázar fechó la pieza hacia 1830, pero su primera publicación fue el 27 de noviembre de 1834 en El Universal. 
que la práctica de aquel comercio debe causar en el corazón de una infeliz africana, a quien le hayan arrebatado sus hijos y su esposo, con el pretexto (aunque fuese plausible para nosotros) de hacerlos Colonos involuntarios de un país que no conocen ${ }^{62}$.

El 13 de marzo de 1835 se difundieron en la capital las primeras noticias sobre el desembarco del patacho portugués Delfina en Maldonado ${ }^{63}$. Los introductores habían escondido a 67 africanos en la Isla de Gorriti, desembarcando al resto en Maldonado para presentarlos ante las autoridades. Posteriormente, intentaron conducir en carretas a los africanos dejados en Gorriti hacia Montevideo, pero esa operación fue descubierta por la policía. Ante esto, se confiscaron los "colonos" para sujetarlos a un patronato que administraría el gobierno ${ }^{64}$. Los derechos de patronato se traspasarían a los vecinos de Maldonado, a razón de 200 pesos por "colono", prolongándose el plazo de servicio hasta los 25 años de edad para los menores y durante 3 años para los mayores. El gobierno de Oribe obtuvo 41.230 pesos por la venta de derechos de patronato. Se dispuso que ese dinero fuera entregado a los africanos una vez que cada uno hubiera terminado el plazo de servicio, pero es difícil que esto último se haya practicado.

Las autoridades no pudieron evitar el desembarco de los "colonos" del Delfina. A causa de las prácticas ilegales de los introductores, el gobierno tomó control sobre los africanos, sujetándolos a un patronato - ahora sí garantido por la policía. Tampoco se los podía dejar en plena libertad pues eran niños y jóvenes. El Uruguay no poseía los medios como para reembarcar a los "colonos" hacia África, ni tampoco podía dejarlos a merced de sus conductores, quienes intentarían venderlos en otros puertos. En cierta forma, la presidencia de Oribe representó un cambio sustancial en la política sobre los "colonos" africanos. El nuevo gobierno intentó reencauzar al país en el camino de la abolición, restringiendo casi totalmente el arribo de nuevos esclavos. La nueva administración intentó hacer cumplir más eficazmente la constitución uruguaya, desplegando mayores contralores políticos y económicos sobre la cosa pública ${ }^{65}$. Como resultado, este gobierno reglamentó africana".

62 El Universal, Montevideo, n. 1656, 17 de marzo de 1835, p. 3, introducción a "La madre

63 El Estandarte Nacional, Montevideo, n. 48, 13 de marzo de 1835, p. 2.

64 El Estandarte Nacional, Montevideo, 20 de marzo de 1835, p. 2, documentos oficiales.

65 Sala y Alonso, op. cit., T. II, p. 197. 
la prohibición constitucional del tráfico de esclavos.

El 13 de marzo de 1835 se prohibió que la patente de navegación expedida por el gobierno uruguayo fuera utilizada para traficar africanos ${ }^{66}$. El 13 de octubre de ese año el gobierno decretó la anulación de toda patente de navegación que permitiera a un buque, ya fuera nacional o extranjero, el tráfico de africanos bajo cualquier denominación ${ }^{67}$. Al parecer, el último barco esclavista arribó a Montevideo el 11 de junio de 1835. El bergantín portugués César Augusto traía "colonos" africanos en razón de un contrato de la administración anterior con Domingo Vázquez. Sus consignatarios no pudieron comunicarse con la nave para cambiar su rumbo hacia otro puerto $^{68}$. Se prohibió el desembarque de los africanos, estableciéndose que el barco podía permanecer un mes como máximo en el puerto, sólo para cargar provisiones. Se realizaría un recuento de los africanos. Si alguno de ellos era desembarcado sin permiso de las autoridades, se procedería a embargar a todo el contingente. Igualmente, si fallecía alguno de los africanos a bordo, no se podía bajar el cuerpo sin el consentimiento de la policía. El César Augusto partió de Montevideo sin desembarcar a sus cautivos, pero se ignora qué rumbo siguió. Ante la posibilidad de que los africanos fueran dejados, y vendidos como esclavos en otras zonas de la costa uruguaya, el Ministro de Gobierno Francisco Llambí envió oficios a los jefes políticos de Maldonado, Canelones, Soriano y Colonia, para impedirlo ${ }^{69}$.

La opinión de la sociedad local hacia los "colonos" africanos fue en general negativa. Como caso extremo, se los inculpó de haber introducido enfermedades, especialmente en Montevideo y Maldonado ${ }^{70}$. Paradójicamente, la vacuna contra la viruela llegó a Montevideo a comienzos del siglo XIX en los brazos de esclavos que habían sido inoculados en Rio de Janeiro, práctica que se habría de reiterar en otras ocasiones ${ }^{71}$. Por otra parte, el contagio debido a la comunicación de "castas" constituía uno de los debates sobre el empleo de nodrizas negras por los sectores altos. Más allá

66 El Universal, Montevideo, n. 1658, 19 de marzo de 1835, p. 2.

67 El Nacional, Montevideo, n. 159, 15 de octubre de 1835, p. 2.

68 El Estandarte Nacional, 13 de junio de 1835, p. 2 y El Nacional, Montevideo, n. 59, 13 de junio de 1835 , p. 2.

69 Pivel Devoto, op. cit., p. XXX.

70 El Nacional, Montevideo, n. 35, 14 de mayo de 1835, p. 2.

71 MARTINEZ MONTERO, Homero. La Esclavitud en el Uruguay Contribución a su estudio histórico-social. Revista Nacional. Montevideo, año IV, tomo XV, número 45, p. 406. 
de estas consideraciones, la prensa consideraba perjudicial la proliferación de los habitantes de origen africano para la sociedad.

El periódico El Moderador, fundado por un grupo de argentinos exiliados en Montevideo ${ }^{72}$, condenó la introducción de esclavos y se pronunció a favor de la humanidad y la civilización ${ }^{73}$. Pero más que oponerse a la esclavitud, sus editoriales parecían haber estado escritos contra la proliferación de la población negra en Uruguay. Refiriéndose al africano recién arribado, señaló: "Lo que él trae al país cuando no sea el jermen de los contagios inherentes al clima que habita, es nada más que una fuerza corporal pero inepta como la de cualquiera potencia física que no se mueve sino por el arte". Además sentenció: "El negro nada sabe, todo es preciso enseñarle y lo que llega a aprender siempre carece de la perfección que da la capacidad propia cultivada por una educación que sigue al hombre en sociedad desde la infancia". Por último, advirtió que si los africanos se integraban a la sociedad "adoptiva" y alcanzaban cierta complejidad de pensamiento, se generaban los excesos cometidos por el abolicionismo norteamericano. Por el contrario, si los dominaba la brutalidad y la violencia, habrían de desatarse sangrientas revueltas, como la ocurrida en Pará en 1835. El editor señaló que las diferencias de color constituían barreras objetivas insalvables, cuidándose de no emitir un juicio de valor sobre ellas.

Con razón o sin ella, la diferencia sola del color pone a gran distancia a un blanco de un negro: nadie sin creerse envilecido lo sentaría a su mesa por ejemplo; y se sublevaría la sociedad entera, si a la hija del último proletario blanco se le ocurriera dar la mano a un negro. Esto es práctico: y de acuerdo con tales ideas la educación que reciben a los hijos de aquellos ya libres, no pasa mucho más allá de la que se da al servicio mismo. ¿Qué es, pues lo que se hace con multiplicar imprudentemente los hombres de color? Aumentar una población enteramente eterojenea, y que hemos de tener deprimida sin remedio: una población, cuyos derechos, aspiraciones y goces sociales han de desmentir siempre la liberalidad de nuestras instituciones y principios $[\ldots]^{74}$.

72 ZINNY, Antonio. Historia de la prensa periódica de la República Oriental del Uruguay 1807-1852. Buenos Aires: Casavalle, 1883. p. 221.

73 El Moderador, Montevideo, n. 4, 26 de noviembre de 1835, p. 3.

74 El Moderador, Montevideo, n. 5, 27 de noviembre de 1835, p. 3. 
El autor comparó el desempeño de la inmigración vasca con los "colonos" africanos, realzando a los primeros y anotando las complicaciones de los segundos. Pronosticó que los "colonos" no podrían superar la inferioridad de condiciones que provenía de su arribo forzado desde África, lo cual tampoco sería logrado por su progenie: "[...] pero no serán sus hijos ciudadanos útiles, sino jornaleros con la degradación de sus padres y que participarán muy luego de la indolencia común del paisanaje pobre”. Ante estas apreciaciones, se percibe cuán difícil pudo ser la integración de los "colonos" africanos en la sociedad uruguaya.

\section{Conclusiones}

El caso de los "colonos" africanos ilustra tanto la continuidad como la renovación de las redes comerciales entre los imperios portugués y español en el Atlántico sur. Estas redes, que habían canalizado la llegada legal e ilegal de bienes y esclavos al Río de la Plata colonial, habrían de continuar vigentes hacia los años 1830 y facilitaron el arribo de esclavos a Rio de Janeiro justo cuando la política anti-esclavista británica y el gobierno brasileño estaban tratando de cortar este tráfico. Los comerciantes esclavistas canalizaron sus viajes a través del Río de la Plata para llevar ilegalmente esclavos a Rio de Janeiro. No obstante, ellos también enviaron africanos esclavizados a Uruguay. De este modo, algunos traficantes brasileños crearon una operación coordinada de tráfico de esclavos, bajo el nombre de "colonos africanos," que involucró a comerciantes de Luanda, Mozambique, Rio de Janeiro y Montevideo hacia mediados de la década de 1830.

El arribo de los "colonos" africanos iba a contramano de la tendencia anti-esclavista establecida en el Río de la Plata postrevolucionario. Primero, las guerras de independencia y las posteriores guerras civiles llevaron a los gobiernos locales a enrolar a cierto número de esclavos, y eventualmente a prometer la libertad de los esclavos que forzadamente tomaban las armas. Segundo, la presión británica sobre estas nacientes repúblicas era significativa en tanto ellas necesitaban reconocimiento internacional y apoyo financiero. Tercero, la retórica de la revolución y la participación de los esclavos en la guerra contribuyeron a crear un ambiente propicio a la 
liquidación de la esclavitud. No resulta extraño que no hubiera opiniones abiertamente pro-esclavistas en la prensa montevideana durante este período. Tanto el tráfico de esclavos como la esclavitud se habían vuelto ideológicamente inaceptables debido a factores locales como internacionales en la América española continental. Debemos señalar que los "colonos" africanos de Montevideo fueron los últimos esclavos traídos directamente de África a alguna de las repúblicas de la América española continental.

La existencia de estos "colonos" africanos de Montevideo simbolizaba la debilidad de Uruguay como estado de derecho y la corrupción de sus autoridades. Asimismo, constituye la muestra más brutal de una ideología utilitarista que insistía en llenar el vacío demográfico a toda costa, incluso a través de la compra de niños africanos. También representaba la continuidad de viejos negocios, como el tráfico de esclavos, para salvar las exhaustas arcas públicas y atraer financistas. Los "colonos" africanos fueron la última generación de esclavos que arribó al Uruguay traída directamente de África y de seguro participó en la Guerra Grande, la Guerra de la Triple Alianza y en los conflictos civiles que devastaron al país durante la segunda mitad del siglo XIX. A pesar de las guerras y de la alta mortalidad entre las clases populares, aún hacia fines de siglo pudieron haber sobrevivido algunos africanos en el territorio uruguayo.

Recebido em 09/09/2009.

Aprovado em 17/04/2010. 